\title{
Leading the way to a European circular bioeconomy strategy
}

Lauri Hetemäki, Marc Hanewinkel, Bart Muys, Markku Ollikainen, Marc Palahí and Antoni Trasobares

Foreword

Esko Aho, Cristina Narbona Ruiz, Göran Persson and Janez Potočnik 


\section{Authors}

Marc Hanewinkel is Professor of Forest Economics and Forest Management in the Faculty of Environment and Natural Resources, University of Freiburg.

Lauri Hetemäki is Assistant Director of the European Forest Institute and Adjunct Professor in the Department of Forest Science, University of Helsinki.

Bart Muys is Professor of Forest Ecology and Management, in the Department of Earth and Environmental Sciences, University of Leuven.

Markku Ollikainen is Professor of Environmental and Resource Economics in the Department of Economics and Management, University of Helsinki and Chair of the Finnish Climate Panel.

Marc Palahí is Director of the European Forest Institute.

Antoni Trasobares is Director of Centre Tecnològic Forestal de Catalunya (CTFC).

\section{Advisors}

Esko Aho is Strategic Advisor for the European Forest Institute and former Prime Minister of Finland (I99I-I995).

Cristina Narbona Ruiz is Counselor, Nuclear Safety Council, and President of the Spanish Socialist Worker's Party (PSOE) and former Minister of Environment, Spain (2004-2008).

Göran Persson is the President of the European Forest Institute's ThinkForest Forum, and former Prime Minister of Sweden (I996-2006).

Janez Potočnik is the Co-Chair of International Resource Panel, United Nations Environment Programme and former European Commissioner (2004-20I4) and former Minister for European Affairs, Slovenia (2002-2004).

ISSN 2343-1229 (print)

ISSN 2343-1237 (online)

ISBN 978-952-5980-39-4 (print)

ISBN 978-952-5980-40-0 (online)

Editor in chief: Pekka Leskinen

Managing editor: Rach Colling

Layout: Grano Oy / Jouni Halonen

Printing: Grano Oy

Disclaimer: The views expressed in this publication are those of the authors and do not necessarily represent those of the European Forest Institute.

Recommended citation: Hetemäki, L., Hanewinkel, M., Muys, B., Ollikainen, M., Palahí, M. and Trasobares, A. 2017. Leading the way to a European circular bioeconomy strategy. From Science to Policy 5. European Forest Institute. 
Esko Aho, Cristina Narbona Ruiz, Göran Persson and Janez Potočnik

Eor the first time in human history, we face the - emergence of a single, tightly coupled human socio-ecological system of planetary scope. The world and Europe are facing unprecedented interconnected challenges which will even strengthen in the coming decades: increasing demand for food, water, materials and energy while mitigating and adapting to climate change and reversing environmental degradation, including biodiversity loss, nutrient emissions and land degradation. Addressing such grand challenges, while supporting social and economic prosperity for a growing population, requires a system change in our economic model.

For 200 years we have had an industrial era built on a fossil-based, linear economy. We have seen the transformation of global societies as never before in human history. The industrial era has delivered economic and demographic growth as well as social and technological progress. Over the last 50 years the global economy has experienced a great acceleration, which has triggered significant global economic convergence and a significant reduction of both poverty and inequality between rich and poor countries. However, poverty and inequality are still an issue, even for developed countries.

The industrial era and its economic acceleration has also resulted in an unprecedented rate of environmental degradation related to economic growth. This is clearly seen when comparing GDP growth with other indicators adjusted for natural capital destruction. The world has grown out of the planet. According to the Global Footprint Network, in 2015, we already used a full 1.6-times the sustainable level of resources in our planet. In two decades it will require two planets to sustain our current economic system.

The context of global and European societies has changed. Now we need a new concept for the new context, a new economic paradigm that puts the basis for human prosperity within the planetary boundaries. The year 2016 was a turning point: the 2030 Agenda for Sustainable Development and its Sustainable development Goals (SDGs) were adopted, and the Paris Agreement on climate change came into effect. These sent out a global political message on the way forward to transform our economic system to end poverty, protect the planet, and ensure prosperity for all.

This requires new concepts to realize these international agreements, and bring them to action. The circular biobased economic paradigm can be this - it builds on the synergies of the circular economy and bioeconomy concepts. These two concepts have so far been developed in parallel, but now need to be connected to reinforce each other.

On 13 February 2012, the European Commission adopted a strategy for "Innovating for Sustainable Growth: A Bioeconomy for Europe". Many European and world countries have developed their own bioeconomy strategies in recent years. In 2017, the EU started to review the existing Bioeconomy Strategy to reflect on its future development. We believe the circular bioeconomy has great potential to catalyse an inclusive European economic, political and societal project that is urgently needed. A project in which economic prosperity is more equally distributed among citizens and placed sustainably within the renewable boundaries of the planet.

The shift to a circular biobased economic paradigm should be a long-term strategy for decoupling economic growth from environmental degradation. It needs to be socially, economically and environmentally sustainable. The story of the first-generation biofuels in the beginning of this century is a lesson from which we should all learn. Science and technology are laying the foundations for the bioeconomy age. Biobased products have emerged that can substitute fossil-based materials like plastics, chemicals, synthetic textiles, cement and many 
other materials. Now the big question is how do we take this scientific and technological success to a scale of economic paradigm shift. How can we ensure that longstanding industries such as the textile, petrochemical, construction and plastic sectors join and even lead this paradigm shift in a sustainable way?

We welcome this report coordinated by the European Forest Institute (EFI). It reflects on the main needs to update existing bioeconomy strategies, connecting to the UN SDGs, the Paris Agreement and other recent developments including the circular economy. It provides strategic recommendations which should be considered when developing a new bioeconomy strategy for Europe, based on sustainability principles. It also provides science-based insights on the potential of forest resources, our main biological infrastructure, and on how forest-based solutions can help to develop the bioeconomy from niche to norm. 


\section{Executive summary}

In 20I6, the Sustainable Development Goals and the Paris Climate Agreement gave global, overarching societal objectives for future decades. The critical question now is how to reach the targets they set. We argue that a necessary part of the answer will be the move to a circular bioeconomy.

It is widely agreed that in order to reach these ambitious global targets, a business-as-usual model will not work. Policies and production and consumption habits will need to change. These global agreements give a mandate to change our existing economic model to one which includes natural capital in the way we advance societal wellbeing. One necessary element in this change is the move to a circular bioeconomy, which increases the use of renewable non-fossil raw materials and products in sustainable, resource-efficient and circular way.

This report analyses what a circular bioeconomy strategy would require, particularly in a European context. Existing bioeconomy strategies have been helpful in demonstrating the need to advance the use of renewable biomass to substitute for fossil-based raw materials and products to create a more sustainable society. A bioeconomy contributes to sustainable economy in general, and engages many industries and services, such as clothing, housing, health, food and transportation. In addition, it is becoming a central element of developing cities worldwide, as a basis of sustainable living and consumption, and providing many services, from food and fresh water supply to recreation and urban cooling.

However, many strategies, for example the EU Bioeconomy Strategy and Action Plan from 20I2, have gaps in scope or focus, and need updating due to major recent changes and new initiatives. Developing a circular bioeconomy strategy for the long-term requires it to be connected across key sectors and policies in a coherent policy framework. There is a need

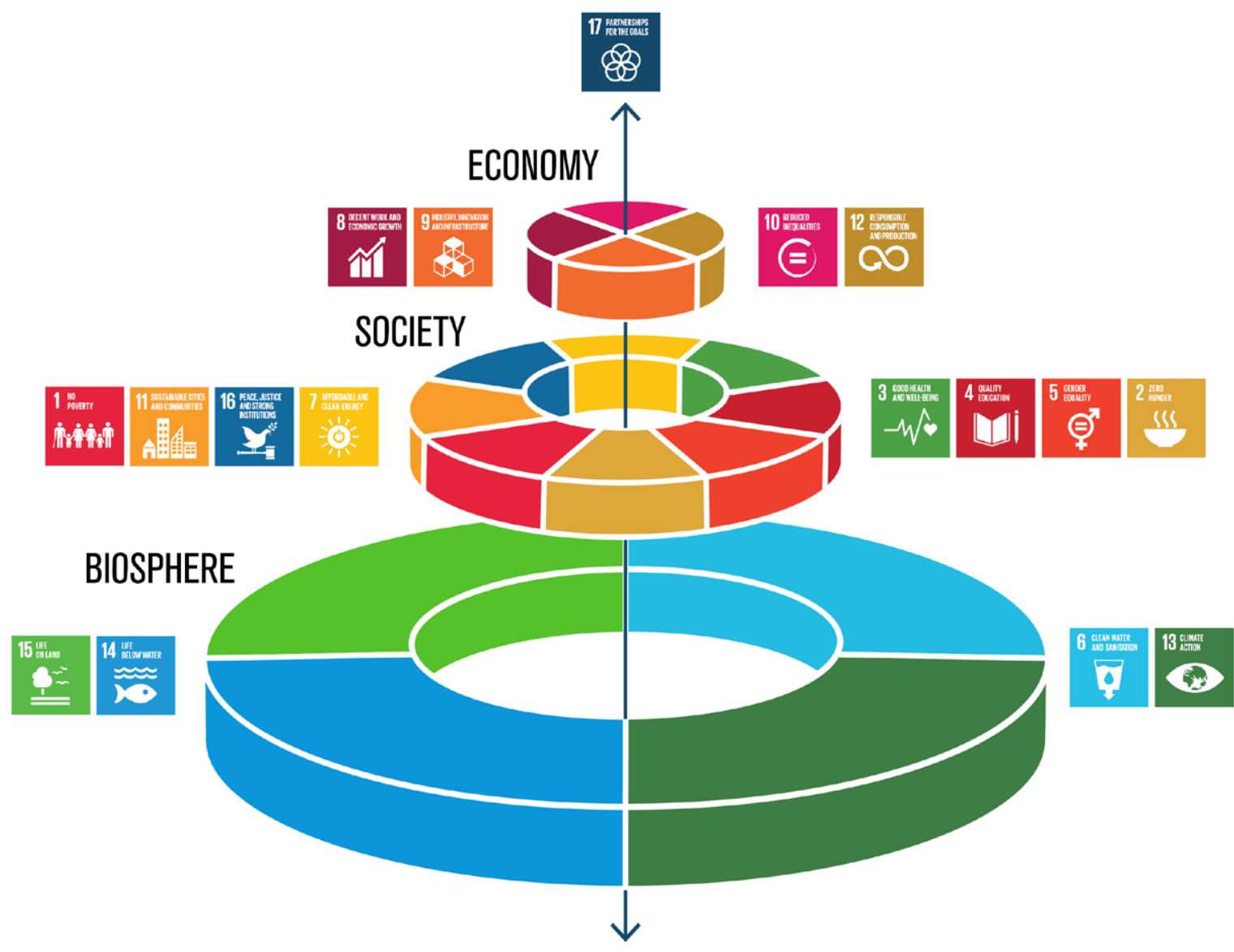

Figure 1. The layers of Sustainable Development Goals that form the basis for a circular bioeconomy strategy. Source: Azote Images for Stockholm Resilience Centre. 
to mainstream bioeconomy within the rest of the economy, not just advance it as a separate sector of interest to mainly rural communities.

In particular, it is crucial to connect bioeconomy to the circular economy concept. Together they are stronger and make more sense in terms of reaching societal goals, than advancing them separately. We should address the following priority elements to transform the circular bioeconomy from niche to norm.

\section{Key recommendations for a circular bioeconomy strategy}

\section{Create a science-based circular bioeconomy narrative}

A socio-economic strategy needs a narrative explaining why it is important. Show how it helps to integrate natural capital in an economic model to decouple economic growth from environmental degradation and achieve the SDGs. The circular bioeconomy narrative should be especially appealing to highly urbanised areas, where the bulk of EU citizens live. The bioeconomy is increasingly relevant and necessary for cities, not only for rural communities, as traditionally emphasized. A narrative is necessary to gain long-term societal engagement (voters) to support circular bioeconomy policies and actions. "No policy - no matter how ingenious - has any chance of success if it is born in the minds of a few and carried in the hearts of none."

\section{Do not assume a bioeconomy is sustainable}

Design policies to support all dimensions of sustainability. This also means giving more attention to social and environmental dimensions than has been the case in current bioeconomy strategies. Connect the circular bioeconomy more directly to climate and environmental policies (e.g., increasing plastic waste in oceans), and the challenges and opportunities they generate for circular bioeconomy development. Maximize synergies and minimize trade-offs between biomass production and ecosystem services (food, biodiversity, recreation, water, etc.). Understand that you cannot have bioeconomy without biodiversity, because biodiversity is a key feature of our natural capital and a basic condition for any

I A quote from Henry Kissinger, former US Secretary of State and political scientist. In the original quote Kissinger referred explicitly to foreign policy, here we use it to apply to all policies. biobased product or service. In a modern society, bioeconomy is often needed to support biodiversity.

\section{Define priority strategic pathways and the} key enabling environment

This should include measures to increase the carbon price (tax, effective ETS) and extend it more widely to direct economies to a low carbon path, in which a bioeconomy will play a crucial role. The need to abolish consumer and producer subsidies supporting the use of fossil fuels is also very urgent, and the possibilities of a tax shift from labour to resource and energy consumption should also be analysed. Additional policies are also needed at a sectoral level, (e.g., construction, chemicals, plastics, textiles, fertilisers, etc.). Provide long-term policies that help to guide major investments to these sectors and make them more sustainable.

\section{Invest in R\&D, innovations and developing new skills}

The circular bioeconomy will be based increasingly on new, innovative, more resource-efficient and circular processes, products and services. R\&D is necessary for the disruptive developments that this requires, e.g., merging digital and biological technologies. Support for basic and applied science and research is essential, but needs to be supplemented with support for business innovation. Skills are crucial for the circular bioeconomy to become mainstream. Improving linkages between researchers, trainers, educators, industry and public administration will be the key. The curricula in universities and applied educational institutes need to be updated, and there is a need for cross-cutting research including economic, political, environmental and foresight research, not just biotechnology, engineering and chemistry.

\section{Provide the right regulatory framework}

This is a key catalyst for the transition from a fossil-based economy to a circular bioeconomy. It requires coordination of all significant policy instruments, including public procurement and infrastructure development and planning, to meet the needs of the strategy and create an enabling architecture. To take one example, public procurement has great potential as a policy instrument, as it represents I4\% of GDP in the EU. Directing public procurement to products and services that are circular, 
biobased and contribute to closing resource loops, can play a significant role. The key target is to have clear, defined roles for both the government providing the regulatory operating environment, and the business sector implementing the investments and business operations. The more complex the operating environment, the more need there is for cooperation between the EU, Member State governments and business.

\section{Enhance risk-taking capacity}

New innovations usually have high risks. A circular bioeconomy will need policies to reduce or share the risks, and high-risk financial mechanisms such as venture-capital funding. For example, in 2016 the EU launched a pan-European Venture Capital Fund(s)-ofFunds programme that could be used to support circular bioeconomy investments. Green bonds are likely to be increasingly important for financing circular bioeconomy investments. The public sector could support high-risk investments, especially when they are thought to have more extensive positive spill-over impacts. This could be e.g. R\&D spending to reduce knowledge-related risks, or investment support for pioneering pilots, demonstration projects, start-ups and mills. Finally, policy actions should demonstrate a long-term, stable regulatory commitment and environment to support circular bioeconomy alternatives to fossil-based products targeting the entire products sector and value chains.

\section{Develop EU-level common standards and regulations}

This is important for the development of new circular bioeconomy products and services. A wellknown past example is the success of the Global System for Mobile Communications (GSM) -standard that was adopted in Europe in I987. New circular bioeconomy products and services would benefit from this type of standard. One example is wood construction, in which the lack of common standards and regulations (e.g. fire regulations) hinders its large-scale deployment in high-rise buildings. Biosourced materials and secondary raw materials are often not 'identical' to virgin raw materials, and may require different safety criteria.

\section{Emphasise biobased services}

The services related to biobased products, such as immaterial rights, servicing, design, R\&D, consulting, marketing, sales and administration will become increasingly important with the development of digital technology and big data. What will this mean for business opportunities, the geographical location of the different value chain parts, skills needs, etc.? In addition, natural resources provide key ecosystem services to society: cultural services (recreation, ecotourism, hunting), regulating services (clean air, erosion control, climate mitigation), and provisioning services (drinking water, non-wood forest products like mushrooms and berries). The opportunities these create, and the policies and actions their development requires, should receive more attention in a new circular bioeconomy strategy.

\section{Make use of the opportunities that forests provide}

The current EU bioeconomy strategy has not sufficiently understood what the forest sector can contribute. Forests are the biggest land-based renewable resource, with the potential to contribute in a far wider way than previously thought. Often the role of forests and the forest sector is seen in a very traditional way - it is about timber, pulp and paper and perhaps bioenergy. This century has shown that the sector is going through major development and diversification, which extends its opportunities and importance. For example, the sector is increasingly entering areas such as textiles, construction, bioplastics, chemicals, and intelligent packaging. In many regions, the services related to forests e.g. in tourism are also developing from niche to significant businesses. All these provide diverse and increasing opportunities to contribute to circular bioeconomy development. 


\section{Acknowledgements}

The report has been written by authors with a scientific background, and the approach has been to try to base the arguments on scientific knowledge, when possible. However, given the strategic nature of the report, and the lack of scientific evidence on some of the issues, we also based the analysis on expert knowledge and our own understanding and views. To support the policy relevance of the report, and to guide its focus, we had the honour to have highly experienced former politicians as 'godfathers and godmother' to our report, and they have also contributed by writing the Foreword. We take the opportunity to express warm thanks to Esko Aho (former Prime Minister, Finland), Cristina Narbona (former Minister of Environment, Spain), Göran Persson (former Prime Minister, Sweden) and Janez Potočnik (former European Commissioner and Minister for European Affairs, Slovenia) for their experienced and insightful advice and support.

The report also benefited from the helpful comments from external reviewers, Christian Patermann, former Director at the European Commission, and Professor Mikael Hildén, Finnish Environment Institute (SYKE). We wish to express our thanks for their insights and comments that helped to improve the report, and acknowledge that they are in no way responsible for any remaining errors.

This work and publication has been financed by EFI's Multi-Donor Trust Fund for policy support, which is supported by the Governments of Austria, Czech Republic, Finland, France, Germany, Ireland, Italy, Norway, Spain and Sweden. Hetemäki also wishes to acknowledge financial support from the FORBIO project (no. 14970) funded by the Strategic Research Council at the Academy of Finland.

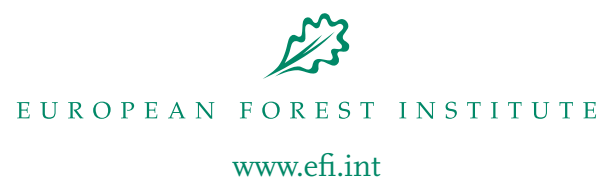

